\title{
Borneol, a Bicyclic Monoterpene Alcohol, Reduces Nociceptive Behavior and Inflammatory Response in Mice
}

\author{
Jackson Roberto Guedes da Silva Almeida, ${ }^{1}$ Grasielly Rocha Souza, \\ Juliane Cabral Silva, ${ }^{1}$ Sarah Raquel Gomes de Lima Saraiva, ${ }^{1}$ Raimundo Gonçalves de \\ Oliveira Júnior, ${ }^{1}$ Jullyana de Souza Siqueira Quintans, ${ }^{2}$ Rosana de Souza Siqueira Barreto, ${ }^{2}$ \\ Leonardo Rigoldi Bonjardim, ${ }^{2}$ Sócrates Cabral de Holanda Cavalcanti, ${ }^{3}$ \\ and Lucindo José Quintans Junior ${ }^{2}$ \\ ${ }^{1}$ Núcleo de Estudos e Pesquisas de Plantas Medicinais, Universidade Federal do Vale do São Francisco, \\ 56.304-205 Petrolina, PE, Brazil \\ ${ }^{2}$ Laboratório de Farmacologia Pré-Clínica, Universidade Federal de Sergipe, 49.000-100 São Cristóvão, SE, Brazil \\ ${ }^{3}$ Departamento de Farmácia, Universidade Federal de Sergipe,49.000-100 São Cristóvão, SE, Brazil
}

Correspondence should be addressed to Jackson Roberto Guedes da Silva Almeida; jackson.guedes@univasf.edu.br

Received 17 February 2013; Accepted 8 March 2013

Academic Editors: N. J. Christensen and M. W. Jann

Copyright (C) 2013 Jackson Roberto Guedes da Silva Almeida et al. This is an open access article distributed under the Creative Commons Attribution License, which permits unrestricted use, distribution, and reproduction in any medium, provided the original work is properly cited.

\begin{abstract}
Borneol, a bicyclic monoterpene, has been evaluated for antinociceptive and anti-inflammatory activities. Antinociceptive and anti-inflammatory activities were studied by measuring nociception by acetic acid, formalin, hot plate, and grip strength tests, while inflammation was prompted by carrageenan-induced peritonitis. The rotarod test was used to evaluate motor coordination. Borneol produced a significant $(P<0.01)$ reduction of the nociceptive behavior at the early and late phases of paw licking and reduced the writhing reflex in mice (formalin and writhing tests, resp.). When the hot plate test was conducted, borneol (in higher dose) produced an inhibition $(P<0.05)$ of the nociceptive behavior. Such results were unlikely to be provoked by motor abnormality. Additionally, borneol-treated mice reduced the carrageenan-induced leukocytes migration to the peritoneal cavity. Together, our results suggest that borneol possess significant central and peripheral antinociceptive activity; it has also anti-inflammatory activity. In addition, borneol did not impair motor coordination.
\end{abstract}

\section{Introduction}

Monoterpenes, belonging to a large and diverse group of chemical compounds named "terpenes," represent a group of naturally occurring organic compounds whose basic structure consists of two linked isoprene units, which are formed by a 5 -carbon base $\left(\mathrm{C}_{5}\right)$ each. They are the most representative molecules constituting $90 \%$ of the essential oils and have a great variety of structures [1], with several pharmacological properties assigned to them, including cardiovascular, antioxidant, anti-inflammatory, and analgesic $[2,3]$.

Borneol $\left(\mathrm{C}_{10} \mathrm{H}_{18} \mathrm{O}\right)$, a bicyclic monoterpenoid alcohol, one of the valuable medical material, senior aromatic spices, and chemical materials, has been used in food and also folk medicine in China and India. According to the Pharmacopoeia of China (2005), borneol is an important ingredient among about 63 herbal products [4]. This compound is considered a GRAS (generally regarded as safe) approved by the FDA (US Food and Drug Administration) as food flavor [5]. Additionally, borneol is a fragrance ingredient used in decorative cosmetics, fine fragrances, shampoos, toilet soaps, and other toiletries as well as in noncosmetic products such as household cleaners and detergents. Its use worldwide is in the region of 10-100 metric tonnes per annum [6].

Previous studies have shown that borneol has vasorelaxant effect on rat thoracic aorta [7] and neuroprotective effects [8]. Despite being inserted in pharmaceutical preparations to treat painful and inflammatory conditions, few studies have 


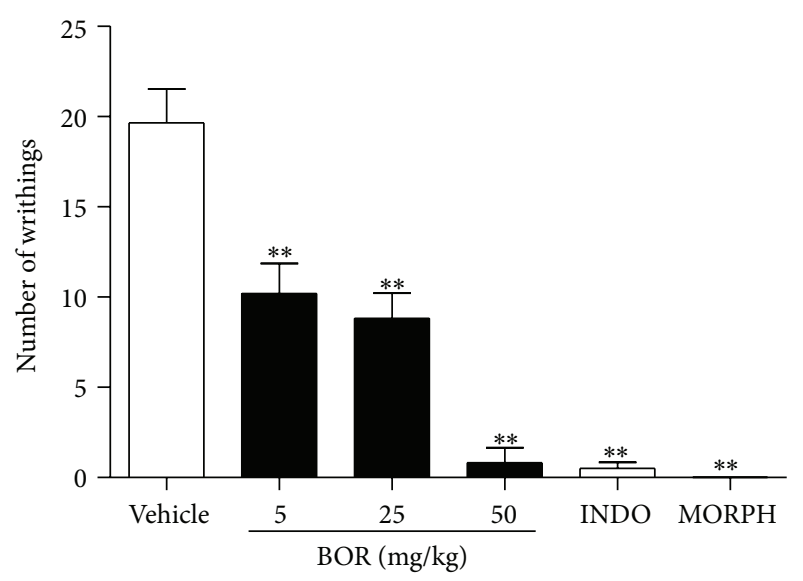

FIGURE 1: Effect of borneol (BOR), indomethacin (INDO $20 \mathrm{mg} / \mathrm{kg}$ ), and morphine (MORPH $10 \mathrm{mg} / \mathrm{kg}$ ) on acetic-acid-induced writhing test. Values are mean \pm S.E.M. ${ }^{* *} P<0.01$, significantly different from control; ANOVA followed by Dunnett's test ( $n=6$, per group).

been found investigating the specific role of borneol in this regard. So, we investigated the possible antinociceptive effect of borneol in rodents.

\section{Material and Methods}

2.1. Animals. Male adult albino Swiss mice $(25-35 \mathrm{~g})$ were used throughout this study. The animals were randomly housed in appropriate cages at $22 \pm 2^{\circ} \mathrm{C}$ on a $12 \mathrm{~h}$ light/dark cycle with free access to food and water. They were used in groups of six animals each. Experimental protocols and procedures were approved by the Universidade Federal do Vale do São Francisco Animal Care and Use Committee by number 024240408.

2.2. Acetic-Acid-Writhing-Induced Nociception. This test was performed using the method described by Koster et al. [9]. Mice were divided into six groups of six mice each. Acetic acid $(0.9 \% \mathrm{v} / \mathrm{v})$ was administered i.p. in a volume of $0.1 \mathrm{~mL} / 10 \mathrm{~g}$. Vehicle (saline), morphine ( $10 \mathrm{mg} / \mathrm{kg}$ ), indomethacin (INDO $20 \mathrm{mg} / \mathrm{kg}$ ), and borneol (BOR 5, 25, and $50 \mathrm{mg} / \mathrm{kg}$ ) were administered i.p. $30 \mathrm{~min}$ before the injection of acetic acid. The number of abdominal constrictions produced in each group for 5-15 min after injection was counted and compared to the response in the control group. Antinociceptive activity was calculated as the percentage inhibition of abdominal constriction.

2.3. Formalin-Induced Nociception. The method used was similar to that described by Hunskaar and Hole [10]. Twenty microliters of $2.5 \%$ formalin (in $0.9 \%$ saline, subplantar) was injected subcutaneously into the right hind paw of the mice. The time (in seconds) spent licking and biting the injected paw was measured as an indicator of pain response. Responses were measured for $5 \mathrm{~min}$ after formalin injection (first phase, neurogenic) and 15-30 min after formalin injection (second phase, inflammatory). Vehicle (saline),

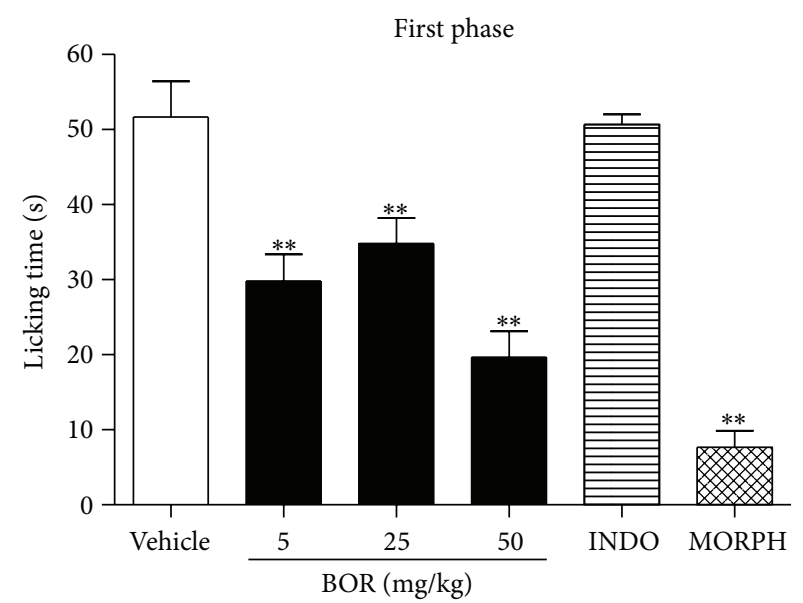

(a)

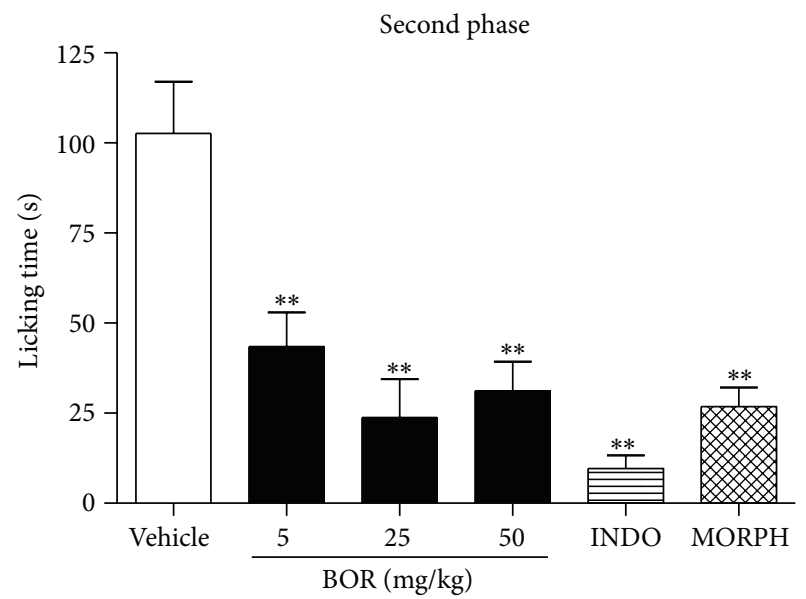

(b)

FIGURE 2: Effect of borneol (BOR), indomethacin (INDO $20 \mathrm{mg} / \mathrm{kg}$ ), and morphine (MORPH $10 \mathrm{mg} / \mathrm{kg}$ ) on first phase (a) and second phase (b) of the formalin test. Values are mean \pm S.E.M.; ${ }^{* *} P<0.01$, significantly different from control; ANOVA followed by Dunnett's test ( $n=6$, per group).

morphine (10 mg/kg), indomethacin (INDO $20 \mathrm{mg} / \mathrm{kg}$ ), and borneol (BOR 5, 25, and $50 \mathrm{mg} / \mathrm{kg}$ ) were administered i.p. $60 \mathrm{~min}$ before the injection of formalin. Mice were observed in the chambers with a mirror mounted on three sides to allow view of all of the paws. Antinociceptive activity was calculated as the percentage inhibition of licking time.

2.4. Hot Plate Test. Mice were divided into five groups of six mice each. Mice were preselected on the hot plate at $55 \pm 0.5^{\circ} \mathrm{C}$. Licks on the rear paws were the parameters of observation. Animals showing a reaction time (defined as the latency for licking the hind feet or jumping) greater than $20 \mathrm{~s}$ were discarded. The animals were then treated with vehicle (saline, $0.1 \mathrm{~mL} / 10 \mathrm{~g}$, i.p.), morphine $(10 \mathrm{mg} / \mathrm{kg}$, i.p.), and borneol (BOR 5, 25, and $50 \mathrm{mg} / \mathrm{kg}$, i.p.). Latency time (in seconds) for each mouse was determined on the hot plate during a maximum period of $20 \mathrm{~s}$, at intervals of 30, 60, 90, 


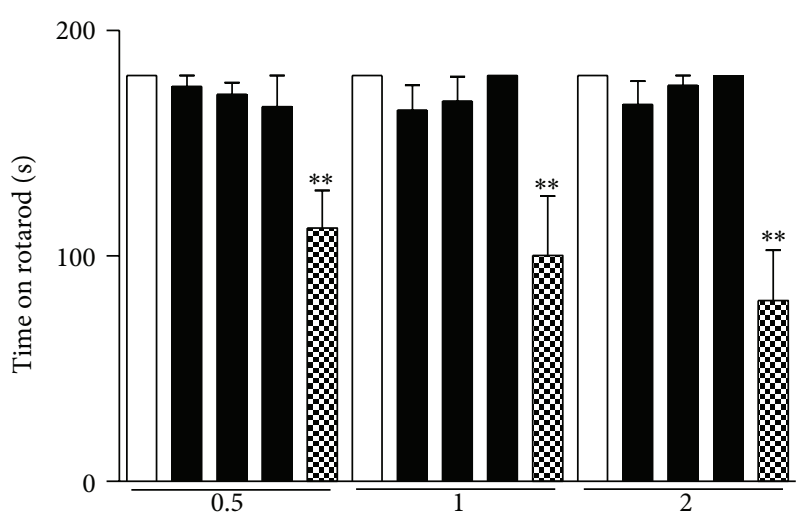

(h)

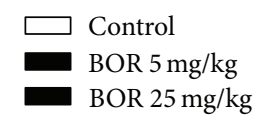

FIGURE 3: Effect of borneol (BOR) and diazepam on rotarod test. Values are mean \pm S.E.M.; ${ }^{* *} P<0.01$, significantly different from control; ANOVA followed by Dunnett's test ( $n=6$, per group).

and $120 \mathrm{~min}$ after the administration of the vehicle, extract, and morphine [11].

2.5. Rotarod Test. A rotarod tread mill device (Insight, Brazil) was used for the evaluation of motor coordination [12]. Initially, $24 \mathrm{~h}$ before the test, mice capable of remaining on the rotarod apparatus longer than $180 \mathrm{~s}(7 \mathrm{rpm})$ were selected. Thirty minutes after the administration of either borneol (BOR 5; 25, and $50 \mathrm{mg} / \mathrm{kg}$, i.p.), vehicle (saline/Tween 80 $0.2 \%$; control group), or diazepam (DZP; $2.5 \mathrm{mg} / \mathrm{kg}$, i.p.), each animal was tested on the rotarod apparatus at $0.5,1$, and $2 \mathrm{~h}$ after treatment, and the time (s) the mice were able to remain on top of the bar was recorded for up to $180 \mathrm{~s}$.

2.6. Grip Strength Test. Grip strength test was performed using a grip strength meter (Model EFF-305, Insight, Ribeirão Preto-SP, Brazil) as previously described [13]. The grip strength meter consists of a force transducer with digital display and a metal plate with a trapeze. Each mouse was placed on the plate and was pulled by its tail with increasing force until it was unable to grasp the trapeze and the grip was broken. The instrument digitally captures and displays the peak pull-force achieved. Muscle strength was defined as the peak weight (g) indicated on the display. The value was determined individually as the mean of three trials and presented as group mean \pm SEM. Mice were treated similarly of the rotarod test.

2.7. Leukocyte Migration to the Peritoneal Cavity. The leukocyte migration was induced by the injection of carrageenan $(500 \mu \mathrm{g} /$ cavity, i.p., $500 \mu \mathrm{L})$ into the peritoneal cavity of mice $1 \mathrm{~h}$ after administration of borneol $(5,25$, and $50 \mathrm{mg} / \mathrm{kg}$, i.p.) or aspirin $(200 \mathrm{mg} / \mathrm{kg}$, i.p.) by the modification of the technique previously described by Bastos et al. [14] and
Leite et al. [15]. The animals ( $n=6$, per group) were euthanized by cervical dislocation $4 \mathrm{~h}$ after carrageenan injection. Shortly after, phosphate buffered saline (PBS) containing EDTA ( $1 \mathrm{mM}$, i.p., $10 \mathrm{~mL})$ was injected. Immediately, a brief massage was done for further fluid collection, which was centrifuged $(2000 \mathrm{rpm}, 5 \mathrm{~min})$ at room temperature. The supernatant was disposed, and $1 \mathrm{~mL}$ of PBS was introduced to the precipitate. An aliquot of $10 \mu \mathrm{L}$ from this suspension was dissolved in $200 \mu \mathrm{L}$ of Turk solution, and the total cells were counted in a Neubauer chamber, under optic microscopy. The results were expressed as the number of leukocytes $/ \mathrm{mL}$. The percentage of the leukocyte inhibition $=(1-T / C) \times$ 100 , where $T$ represents the treated groups leukocyte counts and $C$ represents the control group leukocyte counts [15].

2.8. Statistical Analysis. All data obtained were evaluated by one-way analysis of variance (ANOVA) followed by Dunnett's test. Differences were considered to be statistically significant when $P<0.05$. All statistical analyses were done using Graph Pad Prism 5 (Graph Pad Prism Software Inc., San Diego, CA, USA). The percent of inhibition by an antinociceptive agent was determined for the following formula: \% Inhibition = $100 \times($ control - experiment)/control [16].

\section{Results and Discussion}

The present study demonstrates that borneol $(5,25$ and $50 \mathrm{mg} / \mathrm{kg}$ ) is capable of strongly preventing acetic-acidwrithing-induced nociception in mice when injected into intraperitoneally (i.p.) route before $30 \mathrm{~min}$ acetic acid administration (Figure 1). This is a classical model widely used to screen new agents with analgesic profile where both neurogenic and/or inflammatory pain is involved [17]. In aceticacid-induced abdominal writhing, pain is elicited by the injection of an irritant such as acetic acid into the peritoneal cavity which produces episodes of characteristic stretching (writhing) movements, and inhibition of the number of episodes by analgesics is easily quantifiable [9]. Drugs-like analgesics can inhibit this nociceptive behavior [12].

The systemic administration of borneol, all doses, significantly reduced $(P<0.01)$ pain behavior caused by formalin injection in both phases of the formalin test (Figures 2(a) and 2(b)). This test is a very useful method for not only assessing antinociceptive drugs but also helping in the elucidation of the action mechanism [18]. The subcutaneous injection of formalin in the mice paw induces a biphasic response. The neurogenic phase (first phase) is probably a direct result of stimulation in the paw and reflects centrally mediated pain with release of substance $P$, while the late phase (second phase) is due to the release of histamine, serotonin, bradykinin, and prostaglandins [17].

Since acute treatment with borneol elicited a significantly reduction of painful behavior induced by formalin (in the first phase), this result indicates a possible neurogenic (central) component in analgesic profile of monoterpene. Thus, we conducted a hot plate test to evaluate possible involvement of supraspinal component in this response. This test consists of introducing a mouse into an open-ended cylindrical space 
TABLE 1: Effect of borneol and morphine on hot plate test in mice.

\begin{tabular}{|c|c|c|c|c|c|}
\hline \multirow{2}{*}{ Groups } & \multirow{2}{*}{ Dose (mg/kg) } & \multicolumn{4}{|c|}{ Latency time (s) } \\
\hline & & $0.5 \mathrm{~h}$ & $1 \mathrm{~h}$ & $1.5 \mathrm{~h}$ & $2 \mathrm{~h}$ \\
\hline Vehicle & - & $4.43 \pm 0.48$ & $7.52 \pm 0.74$ & $6.07 \pm 0.70$ & $6.52 \pm 0.76$ \\
\hline \multirow[t]{3}{*}{ Borneol } & 5 & $7.07 \pm 0.42$ & $9.77 \pm 1.28$ & $8.48 \pm 0.83$ & $7.47 \pm 0.41$ \\
\hline & 25 & $8.16 \pm 0.89$ & $7.58 \pm 0.73$ & $9.79 \pm 0.48$ & $8.27 \pm 0.59$ \\
\hline & 50 & $9.86 \pm 0.83^{*}$ & $9.18 \pm 0.65$ & $8.89 \pm 0.91$ & $9.84 \pm 0.92^{*}$ \\
\hline Morphine & 10 & $13.79 \pm 2.52^{* *}$ & $12.19 \pm 1.67^{*}$ & $12.34 \pm 1.75^{* *}$ & $12.80 \pm 1.17^{* *}$ \\
\hline
\end{tabular}

Values are mean \pm SEM, $n=6 ;{ }^{*} P<0.05 ;{ }^{* *} P<0.01$ significantly different from control (ANOVA followed by Dunnett's test).

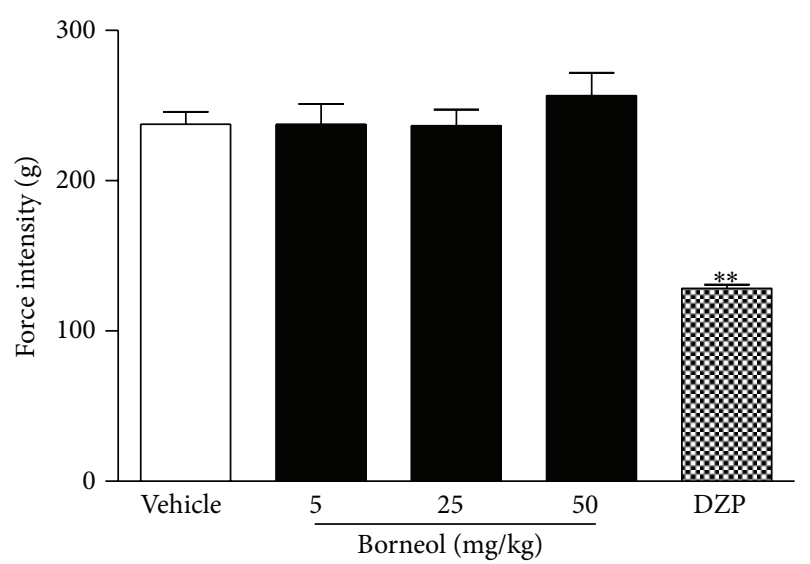

Figure 4: Effect of borneol (BOR) and diazepam $(2.5 \mathrm{mg} / \mathrm{kg})$ on grip strength test. Values are mean \pm SEM.; ${ }^{* *} P<0.01$, significantly different from control; ANOVA followed Dunnett's test $(n=6$, per group).

with a floor consisting of a metallic plate that is heated by a thermode or a boiling liquid [19]. A plate heated to a constant temperature produces two behavioral components that can be measured in terms of their reaction times, namely, paw licking and jumping. Both are considered to be supraspinally integrated responses [17]. The borneol-treated mice lack reduces the painful behavior only in higher dose and at time 0.5 or $2 \mathrm{~h}$ after treatment (Table 1 ). This inconsistent response may have occurred due to a lack effect of borneol on opioid system; after all, the hot plate test is more useful to evaluate opioids drugs [17]. Additionally, this results support the hypothesis that many monoterpenes do not exhibit dosedependent effects [3]; thereby, it is necessary to find the most appropriate dose range that shows effectiveness.

Anyway, according to Granger et al. [20], while many possible mechanisms for the actions of sedative borneol have been proposed, these monoterpenes have been primarily linked, in electrophysiology studies, with functions associated with the neurotransmitter $\mathrm{GABA}_{\mathrm{A}}$. Additionally, Quintans-Júnior et al. [21] reinforce this effect demonstrating that borneol possess anticonvulsant and sedative properties due to the modulation of the GABA system. Several studies demonstrate the hole of GABA system in pain modulation $[22,23]$. Thus, we do not disregard the possibility that the antinociceptive profile of intraperitoneal injected borneol might involve, at least, others central nervous system (CNS)

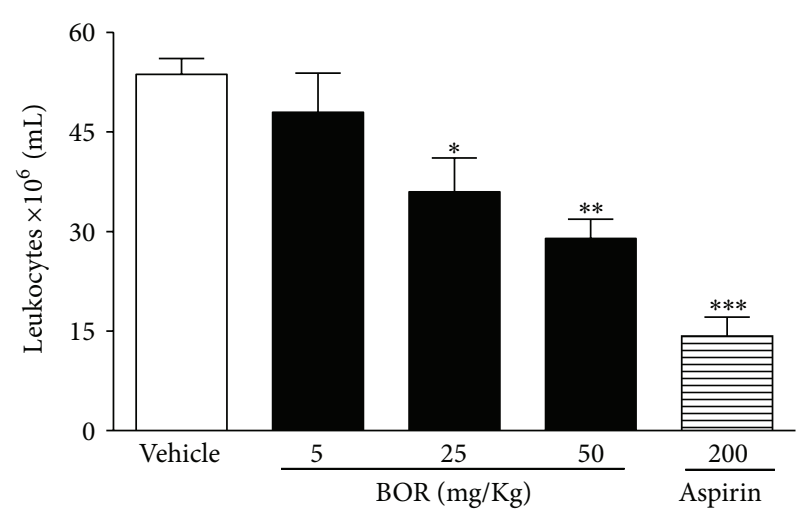

FIGURE 5: Effect of borneol (BOR) and aspirin on leukocyte migration into the peritoneal cavity induced by carrageenan in mice. Groups of rats were pretreated with vehicle (control group), aspirin (200 mg/kg, p.o.), or BOR (5, 25, or $50 \mathrm{mg} / \mathrm{kg}$, i.p.) $60 \mathrm{~min}$ before carrageenan $(500 \mu \mathrm{g} /$ cavity, $500 \mu \mathrm{L}$, i.p.)-induced peritonitis. Cell counts were performed at the time $4 \mathrm{~h}$ after the injection of carrageenan. Each value represents the mean \pm S.E.M. Asterisks denote statistical significance, ${ }^{*} P<0.5,{ }^{* *} P<0.01$, or ${ }^{* * *} P<$ 0.001 related to control group. ANOVA followed by Dunnett's test ( $n=6$, per group).

effects like anticonvulsant or anxiolytic activities and a possible involvement of GABA system.

On the other hand, in order to clarify if the pharmacological effects of borneol would be consequent to a central activity interference on motor function or motor coordination, the activity of borneol was also evaluated on rotarod and grip strength meter apparatus that are classical models for screening CNS or myorelaxant actions providing information about psychomotor performance. As shown in Figures 3 and 4 borneol-treated mice did not cause any motor disturbance on rotarod and grip strength meter test. This effect corroborates that analgesic profile demonstrated by borneol is a direct action in modulate pain by an understanding mechanism.

Since borneol produced a marked analgesic effect in acetic acid writhing-induced nociception and in later phase of formalin test, such that this phase has a strong participation of inflammatory mediators, we investigate the possible effect of borneol on leukocytes migration. Cell recruitment during inflammation depends on the orchestrated release of local mediators that are responsible for local vascular and tissue changes as well as for the recruitment of host defense cells [24]. The inflammation induced by carrageenan involves cell 
migration, plasma exudation, and production of mediators, such as nitric oxide, prostaglandin $\mathrm{E}_{2}$, interleukin (IL) $-1 \beta$, IL-6, and tumor necrosis factor (TNF- $\alpha$ ) [25]. Borneol, in higher doses, reduced leukocyte migration induced by i.p. injection of inflammatory agent (carrageenan) in peritonitis model (Figure 5).

\section{Conclusions}

In summary, it can be concluded that borneol is endowed with peripheral and centrally acting analgesic properties (without producing motor deficit) as well as antiinflammatory profile. However, a more in-depth evaluation of the mechanisms involved should be performed. Our results also support that borneol has a therapeutic potential for painful and inflammatory disorders.

\section{Acknowledgments}

This work was supported by grants from the Conselho Nacional de Desenvolvimento Cientifico e Tecnológico $(\mathrm{CNPq} /$ Brazil $)$ and the Fundação de Apoio à Pesquisa e à Inovação Tecnológica do Estado de Sergipe (FAPITEC-SE/ Brazil).

\section{References}

[1] F. Bakkali, S. Averbeck, D. Averbeck, and M. Idaomar, "Biological effects of essential oils: a review," Food and Chemical Toxicology, vol. 46, no. 2, pp. 446-475, 2008.

[2] M. R. V. Santos, F. V. Moreira, B. P. Fraga, D. P. De Sousa, L. R. Bonjardim, and L. J. Quintans-Junior, "Cardiovascular effects of monoterpenes: a review," Brazilian Journal of Pharmacognosy, vol. 21, no. 4, pp. 764-771, 2011.

[3] A. G. Guimaraes, J. S. S. Quintans, and L. J. Quintans Junior, "Monoterpenes with analgesic activity: a systematic review," Phytotherapy Research, vol. 27, no. 1, pp. 1-15, 2013.

[4] L. Chen, J. Su, L. Li, B. Li, and W. Li, "A new source of natural D-borneol and its characteristic," Journal of Medicinal Plants Research, vol. 5, no. 15, pp. 3440-3447, 2011.

[5] Q. Shen, X. Li, W. Li, and X. Zhao, "Enhanced intestinal absorption of daidzein by borneol/menthol eutectic mixture and microemulsion," AAPS PharmSciTech, vol. 12, pp. 10441049, 2011.

[6] S. P. Bhatia, C. S. Letizia, and A. M. Api, "Fragrance material review on borneol," Food and Chemical Toxicology, vol. 46, supplement 11, pp. S77-S80, 2008.

[7] J. C. Silva-Filho, N. N. P. M. Oliveira, D. D. R. Arcanjo et al., "Investigation of mechanisms involved in (-)-Borneol-induced vasorelaxant response on rat thoracic aorta," Basic and Clinical Pharmacology and Toxicology, vol. 110, pp. 171-177, 2011.

[8] R. Liu, L. Zhang, X. Lan et al., "Protection by borneol on cortical neurons against oxygen-glucose deprivation/reperfusion: Involvement of anti-oxidation and anti-inflammation through nuclear transcription factor אappaB signaling pathway," Neuroscience, vol. 176, pp. 408-419, 2011.

[9] R. Koster, M. Anderson, and E. J. Beer, "Acetic acid for analgesic screening," Federation Proceedings, vol. 18, pp. 412-418, 1959.
[10] S. Hunskaar and K. Hole, "The formalin test in mice: dissociation between inflammatory and non-inflammatory pain," Pain, vol. 30, no. 1, pp. 103-114, 1987.

[11] J. R. G. S. Almeida, J. T. Lima, H. R. Oliveira et al., "Antinociceptive activity of discretamine isolated from Duguetia moricandiana," Natural Product Research, vol. 25, no. 20, pp. 1908-1915, 2011.

[12] P. G. S. de Sá, X. P. Nunes, J. T. de Lima et al., "Antinociceptive effect of ethanolic extract of Selaginella convoluta in mice," BMC Complementary and Alternative Medicine, vol. 12, no. 187, pp. 1-7, 2012.

[13] O. A. Meyer, H. A. Tilson, W. C. Byrd, and M. T. Riley, "A method for the routine assessment of fore- and hindlimb grip strength of rats and mice," Neurobehavioral Toxicology and Teratology, vol. 1, no. 3, pp. 233-236, 1979.

[14] L. F. Bastos, L. A. Merlo, L. T. Rocha, and M. M. Coelho, "Characterization of the antinociceptive and anti-inflammatory activities of doxycycline and minocycline in different experimental models," European Journal of Pharmacology, vol. 576, no. 1-3, pp. 171-179, 2007.

[15] B. L. Leite, R. R. Bonfim, A. R. Antoniolli et al., "Assessment of antinociceptive, anti-inflammatory and antioxidant properties of Cymbopogon winterianus leaf essential oil," Pharmaceutical Biology, vol. 48, no. 10, pp. 1164-1169, 2010.

[16] W. Reanmongkol, K. Matsumoto, H. Watanabe, S. Subhadhirasakul, and S. I. Sakai, "Antinociceptive and antipyretic effects of alkaloids extracted from the stem bark of Hunteria zeylanica," Biological and Pharmaceutical Bulletin, vol. 17, no. 10, pp. 13451350, 1994.

[17] D. Le Bars, M. Gozariu, and S. W. Cadden, "Animal models of nociception," Pharmacological Reviews, vol. 53, no. 4, pp. 597$652,2001$.

[18] A. Tjølsen, O. G. Berge, S. Hunskaar, and J. H. Rosland K Hole, "The formalin test: an evaluation of the method," Pain, vol. 51, no. 1, pp. 5-17, 1992.

[19] N. B. Eddy and D. Leimbach, "Synthetic analgesics: II. Dithenylbutenyl and dithienyl-butylamines," Journal of Pharmacological and Experimental Therapeutics, vol. 107, pp. 385-393, 1953.

[20] R. E. Granger, E. L. Campbell, and G. A. R. Johnston, “(+)- And (-)-borneol: Efficacious positive modulators of GABA action at human recombinant $\alpha 1 \beta 2 \gamma 2 \mathrm{~L} \mathrm{GABA}_{A}$ receptors," Biochemical Pharmacology, vol. 69, no. 7, pp. 1101-1111, 2005.

[21] L. J. Quintans-Júnior, A. G. Guimarães, B. E. S. Araújo et al., "Carvacrol, (-)-borneol and citral reduce convulsant activity in rodents," African Journal of Biotechnology, vol. 9, no. 39, pp. 6566-6572, 2010.

[22] J. Sawynok, "GABAergic mechanisms of analgesia: An update," Pharmacology Biochemistry and Behavior, vol. 26, no. 2, pp. 463-474, 1987.

[23] L. Jasmin, M. V. Wu, and P. T. Ohara, "GABA puts a stop to pain," Current Drug Targets, vol. 3, no. 6, pp. 487-505, 2004.

[24] A. D. Luster, R. Alon, and U. H. von Andrian, "Immune cell migration in inflammation: present and future therapeutic targets," Nature Immunology, vol. 6, no. 12, pp. 1182-1190, 2005.

[25] D. Salvemini, Z. Q. Wang, P. S. Wyatt et al., "Nitric oxide: a key mediator in the early and late phase of carrageenan-induced rat paw inflammation," The British Journal of Pharmacology, vol. 118, no. 4, pp. 829-838, 1996. 

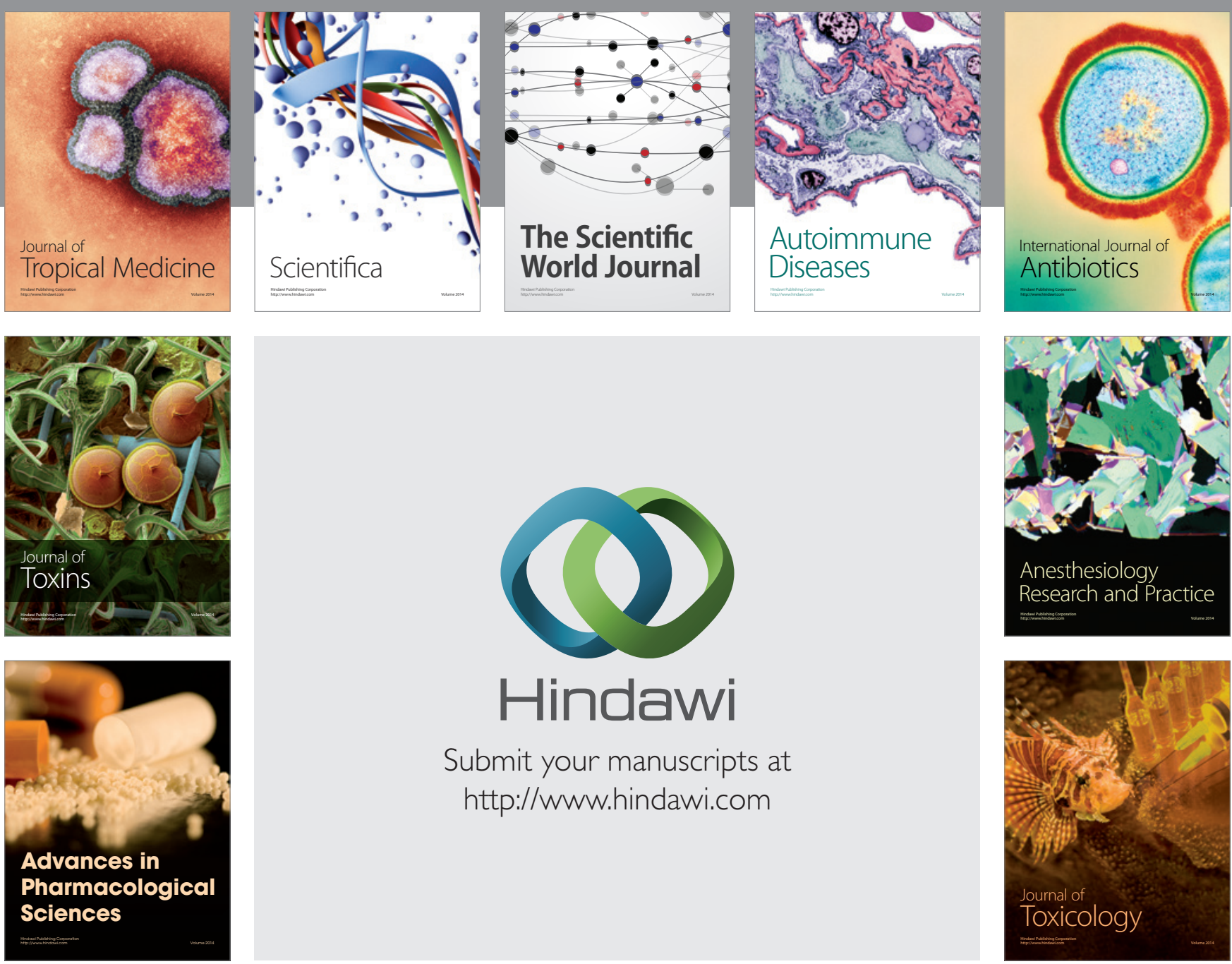

\section{Hindawi}

Submit your manuscripts at

http://www.hindawi.com
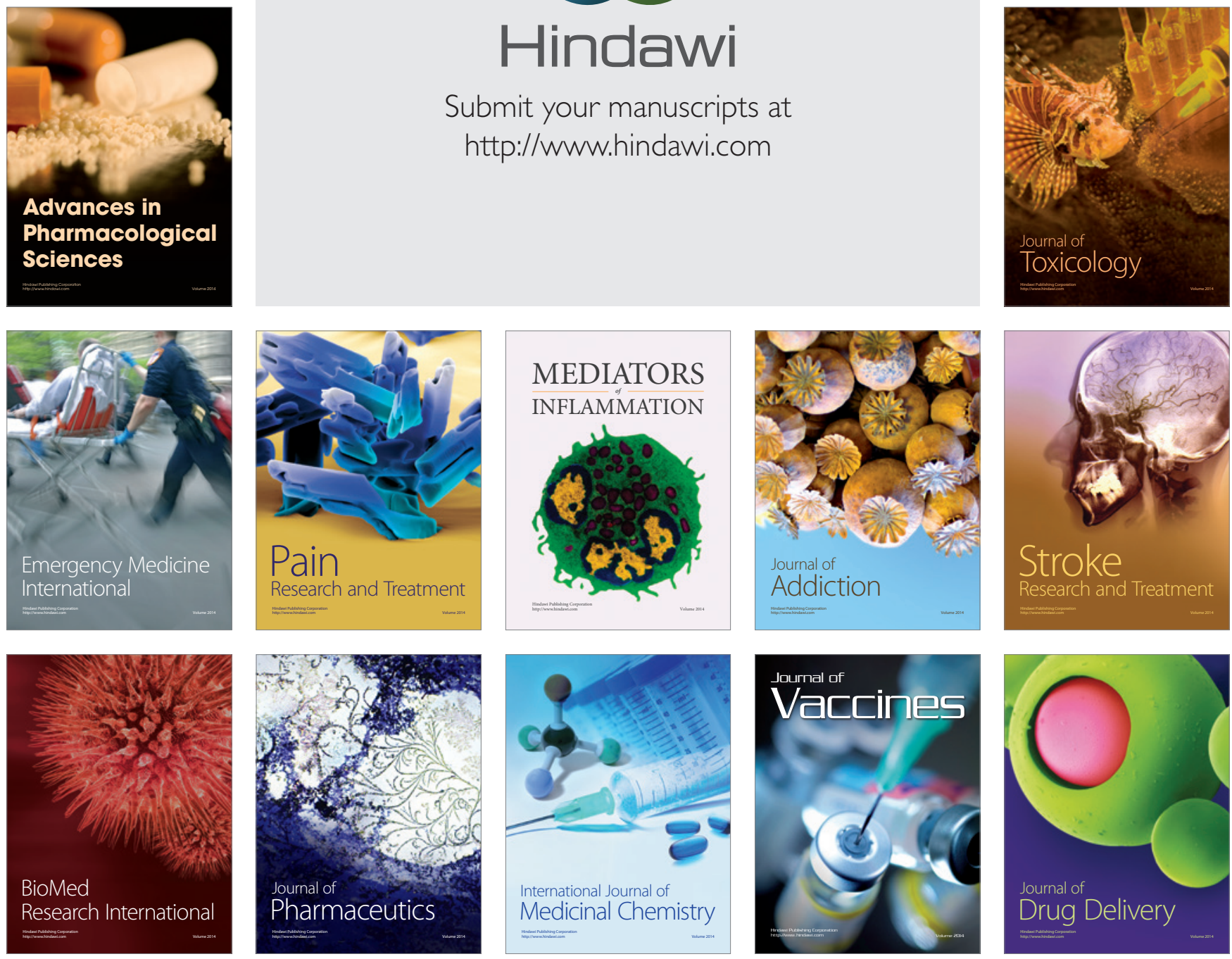